\title{
The Influence of ACE Inhibition on C1-Inhibitor: A Biomarker for ACE Inhibitor-Induced Angioedema?
}

\author{
Janina Hahn ${ }^{a} \quad$ Melanie Nordmann-Kleiner ${ }^{a} \quad$ Christoph Bönner ${ }^{b}$ \\ Georg Kojda ${ }^{c}$ Thomas K. Hoffmann ${ }^{a}$ Jens Greve ${ }^{a}$ \\ a Department of Otorhinolaryngology, Head and Neck Surgery, Ulm University Medical \\ Center, Ulm, Germany; ${ }^{b}$ Department of Cardiology, Internal Medicine II, Ulm University \\ Medical Center, Ulm, Germany; ${ }^{C}$ Institute of Pharmacology and Clinical Pharmacology, \\ Düsseldorf University Hospital, Düsseldorf, Germany
}

\section{What Is It About?}

- The pathomechanism of angiotensin-converting enzyme (ACE) inhibitor-induced angioedema is not yet fully understood. Bradykinin seems to play a major role in the development of edema.

- We aimed to analyze the influence of ACE inhibitor treatment on C1-inhibitor (C1-INH) levels. Two study sections were included: captopril was added to blood samples of 5 healthy subjects, and C1-INH levels were measured. The second section was done with 17 patients who received therapy with an ACE inhibitor.

- A dose-dependent effect on C1-INH levels in captopril-incubated blood samples of healthy test persons was shown. In patients with ACE inhibitor treatment, heterogeneous reactions of C1-INH values were detected.

\section{Keywords}

Angiotensin-converting enzyme inhibitor $\cdot \mathrm{C} 1$-inhibitor $\cdot$ Angioedema $\cdot$ Bradykinin

\section{Abstract}

Aims: Angioedema is a rare side effect of angiotensin-converting enzyme (ACE) inhibitors. It remains unclear why it is only induced in a few patients taking ACE inhibitors, often after a long period of uneventful treatment. The aim of this study was to analyze the influence of ACE inhibitor treatment on C1-inhibitor ( 1 - INH) levels. Methods: Captopril (5 mg/25 mg) was added to blood samples of 5 healthy subjects. $\mathrm{C} 1-\mathrm{INH}$ levels were measured before and after

J. Hahn and M. Nordmann-Kleiner contributed equally to this study. 
incubation for $180 \mathrm{~min}$. The second section of the study was done with 17 patients who received therapy with an ACE inhibitor for the first time. C1-INH levels were measured before ACE inhibitor treatment, $24 \mathrm{~h}$ after first drug administration, and 4 weeks later. Results: After incubation of blood samples with $5 \mathrm{mg}$ captopril, there was no detectable change in C1-INH levels. After incubation with $25 \mathrm{mg}, \mathrm{C} 1-\mathrm{INH}$ activity was decreased by an average of $29 \%$ and the $\mathrm{C} 1-\mathrm{INH}$ concentration was decreased by an average of $0.06 \mathrm{~g} / \mathrm{L}$. In the second study section, inconsistent effects on C1-INH levels were detected. In the majority of patients, $24 \mathrm{~h}$ after the first ACE inhibitor administration C1-INH activity was tending to be increased. Conclusions: A dose-dependent effect on C1-INH levels in captopril-incubated blood samples of healthy test persons was shown. In patients with new ACE inhibitor treatment, heterogeneous reactions of $\mathrm{C} 1-\mathrm{INH}$ values were detected. Larger studies are needed over a longer period of time to find correlations between the effect of ACE inhibitor therapy on C1-INH levels and the clinical course/development of side effects.

(c) 2019 The Author(s)

Published by S. Karger AG, Basel

\section{Introduction}

Angiotensin-converting enzyme (ACE) inhibitors are frequently prescribed drugs for the therapy of primary hypertension and heart failure with a reduced ejection fraction. They inhibit the conversion of angiotensin I into angiotensin II and are expected to prevent cardiovascular, cerebrovascular, and renal complications associated with persistent high blood pressure as well as deterioration of heart failure $[1,2]$.

ACE inhibitor-induced (ACEi) angioedema (AE) is a rare side effect. A systematic investigation of epidemiological studies found an estimated prevalence of ACEi AE between 0.7 and 1.7 per 10,000 inhabitants in the USA and between 1.0 and 2.6 per 10,000 inhabitants in Germany [3]. The weighted incidence of AE due to ACE inhibitor treatment was $0.3 \%$ in a large meta-analysis of randomized trials [4]. Interestingly, the risk of ACEi AE is significantly increased in African Americans [4, 5].

ACEi AE is predominantly located in the head and neck region, i.e., the lips, face, tongue, pharynx, and larynx [6]. AE manifestation in the upper airway region can be life-threatening due to its unpredictable clinical course. ACE is one of the main degradation enzymes of bradykinin - therefore, it is assumed that the iatrogenic inhibition of ACE leads to an increase in bradykinin levels [7]. Bradykinin in turn signals mainly via the constitutively expressed bradykinin receptor $\mathrm{B}_{2}(\mathrm{~B} 2 \mathrm{R})$ and leads to vasodilatation and increases vascular permeability [8]. The downstream mechanisms of bradykinin include the phospholipase $\mathrm{C}$ pathway, leading to inositol triphosphate formation and intracellular $\mathrm{Ca}^{2+}$ mobilization, and the phospholipase A2 pathway, resulting in arachidonic acid release; bradykinin furthermore stimulates endothelial nitric oxide synthase [9-11]. However, it remains unclear which of these signal transduction events are involved to a greater or lesser extent in nonallergic AE.

In the majority of patients, ACEi AE develops in the first weeks of treatment; nevertheless, it can occur even after several years of uneventful ACE inhibitor treatment $[6,12]$. There is no officially approved therapy for ACEi AE. Therefore, it is often primarily treated the same way as mast cell-mediated AE, i.e., with glucocorticoids and antihistamines. In severe cases and if available - the B2R antagonist icatibant or a C1-inhibitor (C1-INH) concentrate can be applied. Both therapies have been approved over the years for the therapy of hereditary AE (HAE), a rare autosomal dominant disorder caused by a mutation in the C1-INH coding gene SERPING1 $[13,14]$. C1-INH - a member of the serine protease inhibitor (serpin) family - has a breaking function in the synthesis of bradykinin [15]. In HAE, C1-INH is either deficient (decreased C1-INH concentration and C1-INH activity) or nonfunctioning (normal 


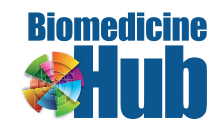

\begin{tabular}{l|l}
\hline Biomed Hub 2019;4:499075 \\
\hline DOI: 10.1159/000499075 & $\begin{array}{l}\text { @ 2019 The Author(s). Published by S. Karger AG, Basel } \\
\text { www.karger.com/bmh }\end{array}$ \\
\hline
\end{tabular}

Hahn et al.: Influence of ACE Inhibition on C1-Inhibitor Levels

Table 1. Data on patients with severe ACE inhibitor-induced angioedema

\begin{tabular}{llcllll}
\hline Sex & $\begin{array}{l}\text { ACE } \\
\text { inhibitor }\end{array}$ & Dose, mg & $\begin{array}{l}\text { Approximate period } \\
\text { of ACE inhibitor } \\
\text { treatment, years }\end{array}$ & $\begin{array}{l}\text { ACE activity } \\
\text { (normal range), } \\
\text { U/L }\end{array}$ & $\begin{array}{l}\text { C1-INH concentration } \\
\text { (normal range), g/L }\end{array}$ & $\begin{array}{l}\text { C1-INH activity } \\
\text { (normal range), \% }\end{array}$ \\
\hline F & ramipril & $5(1-0-1)$ & 5 & $<12(20-70)$ & $0.49(0.17-0.44)$ & $>150(70-130)$ \\
M & enalapril & $10(1-0-0)$ & 15 & $6.1(8-52)$ & $0.48(0.17-0.44)$ & $132(70-130)$ \\
M & ramipril & $10(0-1-0)$ & 2 & $5.2(8-52)$ & $0.21(0.17-0.44)$ & $139(70-130)$ \\
F & lisinopril & $20(1-0-1 / 2)$ & 10 & $6.1(8-52)$ & $0.51(0.17-0.44)$ & $>150(70-130)$ \\
F & ramipril & $5(1-0-0)$ & 12 & $4.3(8-52)$ & $0.32(0.17-0.44)$ & $136(70-130)$ \\
M & ramipril & $5(1-0-1)$ & 2 & $6.0(8-52)$ & $0.49(0.17-0.44)$ & $150(70-130)$ \\
M & ramipril & $5(1-0-0)$ & 4 & $<12(20-70)$ & not available & $111(70-130)$ \\
F & ramipril & $5(1-0-0)$ & 6 & $<12(20-70)$ & $0.38(0.17-0.44)$ & $122(70-130)$ \\
\hline
\end{tabular}

Normal ranges in ACE activity differ due to different laboratories. ACE, angiotensin-converting enzyme; C1-INH, C1-inhibitor.

or increased C1-INH concentration but decreased C1-INH activity), leading to uncontrolled generation of bradykinin. A third and rarer form of HAE with normal C1-INH levels is likely mediated by increased activity of factor XII due to a mutation inducing defective glycosylation [16].

Based on current research results, it is discussed whether icatibant and C1-INH concentrate are effective in the acute treatment of ACEi AE. The available studies show inconsistent data; nevertheless, a high proportion of publications report successful treatment of ACEi AE with intravenous C1-INH or subcutaneous administration of icatibant [17-20].

We analyzed laboratory results from patients who presented with acute ACEi AE. In 8 inpatient cases during the last 3 years, we analyzed C1-INH values and ACE activity in blood samples and found increased C1-INH activity while - as expected - ACE activity was decreased (Table 1). In the present study, we aimed to analyze the influence of ACE inhibitor treatment on C1-INH levels.

\section{Methods}

Section 1: Blood Samples of Healthy Subjects

Inclusion criteria were the absence of a diagnosis of HAE and no present or planned therapy with an ACE inhibitor. Only adult persons were included. Immunosuppressive therapy and/or acute or chronic inflammation were exclusion criteria.

The primary endpoints were the change in C1-INH activity and the C1-INH concentration after addition of the ACE inhibitor captopril. The secondary endpoint was the dose dependency (ACE inhibitor dose and the change in ACE activity). There were two reasons why captopril was chosen as the ACE inhibitor: (1) the prodrug of captopril needs no enzymatic activation and (2) it is soluble in water.

Three citrate containers (each $2.7 \mathrm{~mL}$ ) and 3 serum tubes (each $4.9 \mathrm{~mL}$ ) were filled with blood from each subject. One citrate container and 1 serum tube are needed for measurement of C1-INH activity, the C1-INH concentration, and ACE activity. One citrate container and 1 serum tube from each test person were directly incubated as a control for $180 \mathrm{~min}\left(37^{\circ} \mathrm{C}, 4 \%\right.$ $\left.\mathrm{CO}_{2}\right)$, centrifuged $\left(4,400 \mathrm{rpm}, 15 \mathrm{~min}, 20^{\circ} \mathrm{C}\right)$, frozen $\left(-20^{\circ} \mathrm{C}\right)$, and sent to the specialized laboratory Dr. Limbach \& Kollegen, Heidelberg, Germany. To 1 citrate container and 1 serum tube from each subject, $5 \mathrm{mg}$ captopril was added; to the remaining pair of tubes, $25 \mathrm{mg}$ captopril was added. They were all incubated for $180 \mathrm{~min}\left(37^{\circ} \mathrm{C}, 4 \% \mathrm{CO}_{2}\right)$, then centrifuged $(4,400 \mathrm{rpm}$, 
Table 2. Results of the first study section

\begin{tabular}{|c|c|c|c|}
\hline & No captopril & +5 mg captopril & +25 mg captopril \\
\hline \multicolumn{4}{|l|}{ Subject 1} \\
\hline \multicolumn{4}{|l|}{ C1-INH concentration } \\
\hline $\begin{array}{l}\text { (normal range: } 0.17-0.44 \text { ), g/L } \\
\text { C1-INH activity }\end{array}$ & 0.26 & 0.27 & 0.21 \\
\hline (normal range: 70-130), \% & 95 & 94 & 56 \\
\hline \multicolumn{4}{|l|}{ Subject 2} \\
\hline \multicolumn{4}{|l|}{ C1-INH concentration } \\
\hline C1-INH activity & 0.27 & 0.28 & 0.21 \\
\hline (normal range: 70-130), \% & 100 & 100 & 60 \\
\hline \multicolumn{4}{|l|}{ Subject 3} \\
\hline \multicolumn{4}{|l|}{ C1-INH concentration } \\
\hline $\begin{array}{l}\text { (normal range: } 0.17-0.44 \text { ), g/L } \\
\text { C1-INH activity }\end{array}$ & 0.24 & 0.24 & 0.16 \\
\hline (normal range: 70-130), \% & 86 & 85 & 60 \\
\hline \multicolumn{4}{|l|}{ Subject 4} \\
\hline \multicolumn{4}{|l|}{ C1-INH concentration } \\
\hline $\begin{array}{l}\text { (normal range: } 0.17-0.44 \text { ), g/L } \\
\text { C1-INH activity }\end{array}$ & 0.25 & 0.25 & 0.22 \\
\hline (normal range: 70-130), \% & 93 & 87 & 68 \\
\hline \multicolumn{4}{|l|}{ Subject 5} \\
\hline $\begin{array}{l}\text { C1-INH concentration } \\
\text { (normal range: } 0.17-0.44 \text { ), g/L } \\
\text { C1-INH activity }\end{array}$ & 0.30 & 0.31 & 0.22 \\
\hline (normal range: 70-130), \% & 110 & 107 & 96 \\
\hline
\end{tabular}

C1-INH, C1-inhibitor.

$\left.15 \mathrm{~min}, 20^{\circ} \mathrm{C}\right)$, frozen $\left(-20^{\circ} \mathrm{C}\right)$, and sent to the abovementioned laboratory. The experimental setup was based upon methods from a dissertation about the influence of ACE inhibitors on cellular function [21].

Section 2: Blood Samples of Patients before and after ACE Inhibitor Therapy

The second section was performed in cooperation with the Department of Cardiology, Internal Medicine II, Ulm University Medical Center, Ulm, Germany, to find and recruit patients with ACE inhibitors as new regular treatment. The inclusion and exclusion criteria were the same as mentioned above, except that planned therapy with an ACE inhibitor was a fundamental inclusion criterion.

The primary endpoints were the changes in C1-INH activity and concentration $24 \mathrm{~h}$ and at least 4 weeks after ACE inhibitor treatment initiation. Three dates were settled for collecting blood samples of the patients: before starting the ACE inhibitor therapy (study visit 1), $24 \mathrm{~h}$ after first medication intake (study visit 2), and 4 weeks later (study visit 3). The blood samples consisted of 2 serum tubes and 1 citrate container each. All blood samples were sent for C1-INH value analysis to the laboratory Dr. Limbach \& Kollegen.

Statistical analysis of both study sections was done using IBM SPSS Statistics 21 and by performing an analysis of variance (ANOVA). Statistical significance was set at $p<0.05$. 
Fig. 1. Boxplot summarizing the effects of 0,5 , and $25 \mathrm{mg}$ captopril on the C1-INH concentration in blood samples (ANOVA). C1-INH, C1-inhibitor.

Fig. 2. Boxplot summarizing the effects of 0, 5, and $25 \mathrm{mg}$ captopril on C1-INH activity in blood samples (ANOVA). C1-INH, C1-inhibitor.
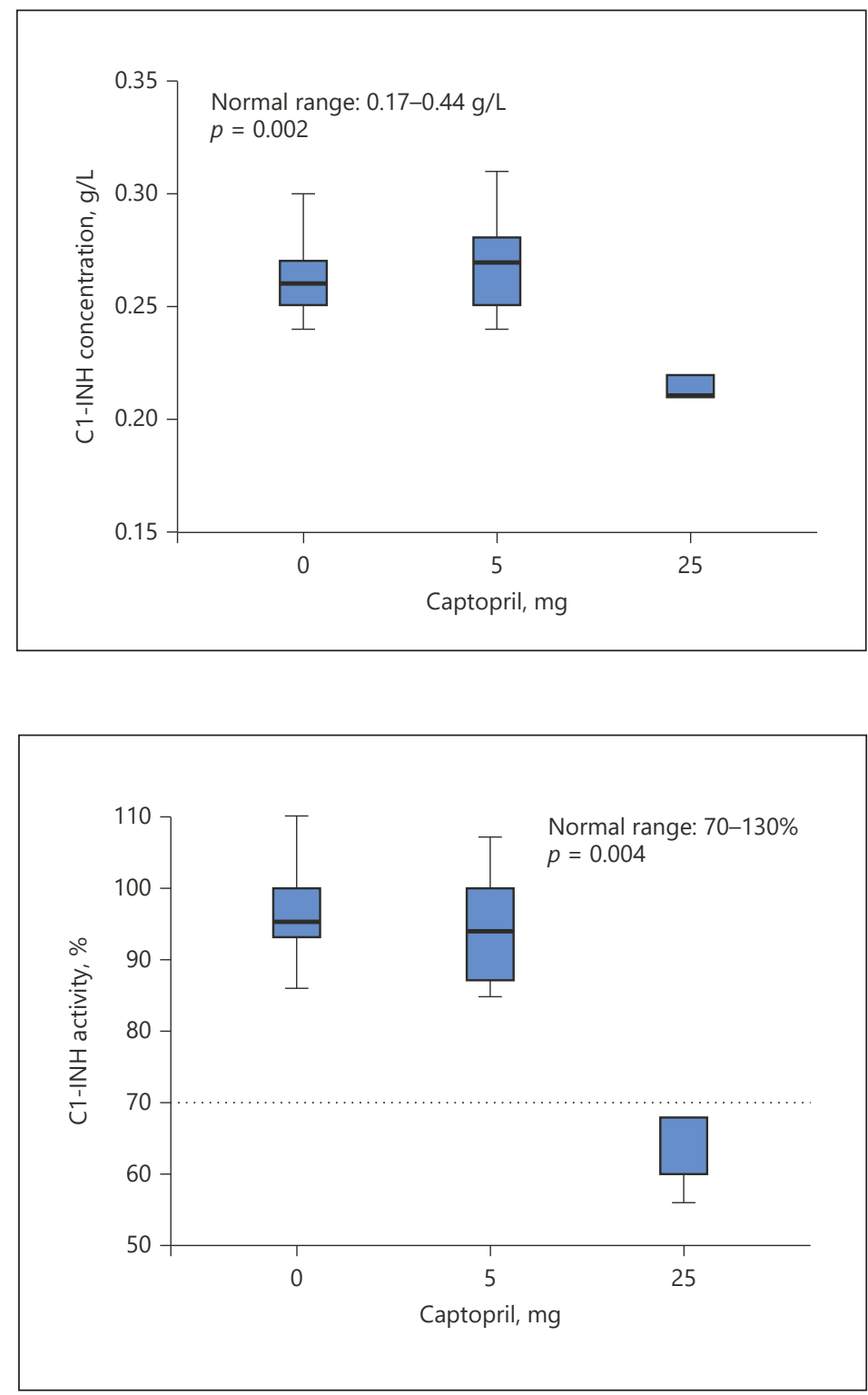

\section{Results}

\section{Section 1}

Five healthy test persons ( 3 female and 2 male) were included in the first study section. The age range of the subjects was 26-43 years, and the average age was 33 years.

The values for C1-INH activity and C1-INH concentration stayed almost constant after addition of $5 \mathrm{mg}$ captopril and $180 \mathrm{~min}$ of incubation in comparison to $180 \mathrm{~min}$ of incubation alone (Table 2).

After addition of $25 \mathrm{mg}$ captopril, a significant decrease in C1-INH concentration was found in all test persons (ANOVA, $p=0.002$; Fig. 1). In only 1 subject, the decrease was slightly below the normal range $(0.16 \mathrm{~g} / \mathrm{L}$; normal range: $0.17-0.44 \mathrm{~g} / \mathrm{L})$, whereas the other 4 test persons presented values within the normal range. 
Fig. 3. a Summary of the effects on the C1-INH concentration. b Summary of the effects on C1INH activity. Study visit 1: before first ACE inhibitor administration; study visit 2: $24 \mathrm{~h}$ after first ACE inhibitor administration; study visit 3: 4 weeks after first C1-INH administration. ACE, angiotensin-converting enzyme; $\mathrm{C} 1$ INH, C1-inhibitor; P, patient.

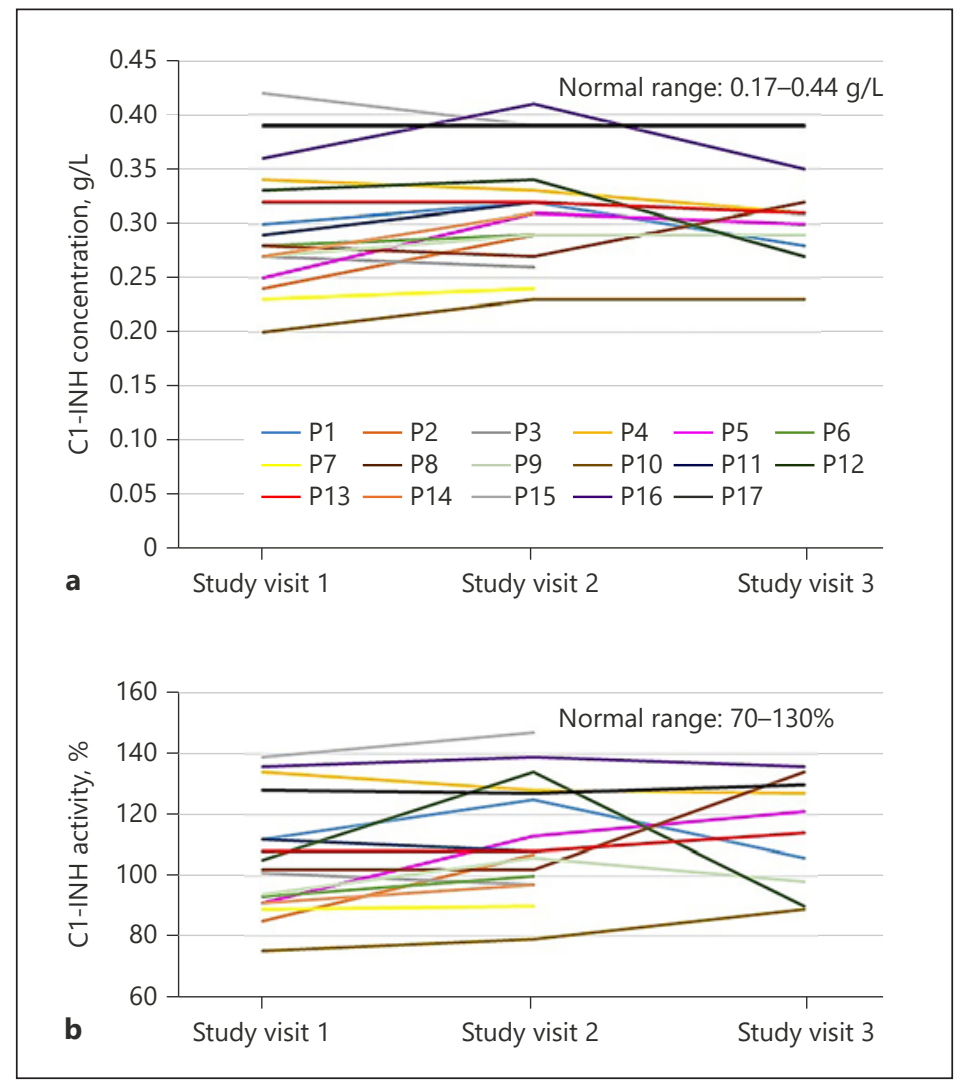

We also observed a significant decrease in C1-INH activity in all subjects after addition of $25 \mathrm{mg}$ captopril and $180 \mathrm{~min}$ of incubation (ANOVA, $p=0.004$; Fig. 2). In 4 of the 5 test persons, the decrease was below the normal range.

\section{Section 2}

Seventeen patients ( 5 female and 12 male) were included in the second part of the study. The age range of the participants was 39-81 years, and the average age was 61 years. All patients received their first ACE inhibitor therapy with ramipril either at the Department of Otorhinolaryngology, Head and Neck Surgery, or at the Department of Cardiology, Internal Medicine II, Ulm University Medical Center. The dosage of ramipril ranged between 2.5 and $10 \mathrm{mg}$ daily. Unfortunately, 7 patients did not complete the third study visit after at least 4 weeks; thus, only data from 10 patients were analyzed concerning "long-term" effects. Five patients failed to appear, 1 patient had to change the ACE inhibitor to an alternative therapy due to dry cough, and 1 patient stopped the therapy due to hypotonic blood pressure values.

Among the measurements of C1-INH values in the second study part, no significant change could generally be detected (Fig. 3). The most frequently observed effects were increases in C1-INH activity and C1-INH concentration, but the effects on both C1-INH values were individual and incoherent. In the following, the second study visit is described as an example: in 9 patients, C1-INH activity and the C1-INH concentration increased $24 \mathrm{~h}$ after the first ramipril administration, in 2 patients a decrease in both values was detected, 4 patients showed no change in either C1-INH activity or C1-INH concentration, and in 2 patients one of the two laboratory values had decreased and one increased. All the results are summarized in Figure 3. 
We performed a correlation analysis between C1-INH activity and C1-INH concentration. There was a strong positive correlation at study visit 1 ( $r=0.929, p=0.01$; Pearson), at study visit 2 ( $r=0.898, p=0.01$; Pearson), and at study visit 3 ( $r=0.850, p=0.01$; Pearson).

We tried to find any correlations with comorbidities, sex, side effects, other medication intake, or any known patient characteristics. Two interesting findings will be mentioned, but as the cohort was too small to form subgroups, larger studies are needed to ascertain whether any further statements can be made based on these findings. One patient (P7; Fig. 3) developed dry cough as a side effect, which is why the medication had to be changed and only the second study visit after $24 \mathrm{~h}$ could be performed. This patient was one of the 4 patients with no change in either C1-INH activity or concentration. Another patient (P2; Fig. 3) had sitagliptin as the regular medication. Sitagliptin inhibits dipeptidyl peptidase 4, another enzyme for bradykinin degradation. This patient exhibited a comparatively strong increase in both C1-INH activity and C1-INH concentration.

In the second study part, no correlation between the prescribed ramipril dosages and the C1-INH values could be observed.

\section{Discussion}

The evaluation of molecular markers that characterize ACEi AE and the search for predictors of the risk of developing an ACEi AE are elemental parts of AE research projects $[22,23]$. To date, no convincing marker has been found or taken over into clinical routine. Based on the findings in 8 patients with ACEi AE, we analyzed the influence of ACE inhibition on C1-INH values in two study parts.

In the first study section, we observed a significant and dose-dependent decrease in C1-INH concentration and C1-INH activity $3 \mathrm{~h}$ after addition of $25 \mathrm{mg}$ captopril to the blood samples of all subjects. A possible explanation for this finding is that elevated bradykinin levels lead to an increased use of C1-INH, and as C1-INH is primarily synthesized in the liver and also produced in monocytes, skin fibroblasts, and endothelial cells [15], C1-INH cannot be refilled in vitro. Therefore, a state of consumption explains the significantly decreased C1-INH values $3 \mathrm{~h}$ after addition of $25 \mathrm{mg}$ captopril. The present results clearly demonstrate an interaction between ACE inhibition and C1-INH values, but also the limitations of an in vitro setting for this purpose.

The second study section with patients new on ACE inhibitor treatment showed individual courses of C1-INH concentrations and C1-INH activity. In our small group of patients, no association with any of the clinical characteristics could be detected. It is obvious that a higher number of patients are needed to carry out further statistical evaluations. Returning to the initial question, the individual courses of C1-INH values before and after ACE inhibitor treatment do not exclude them from their use as a biomarker for ACEi AE, but this requires further investigation.

To our knowledge, we are the first to describe an increase in C1-INH activity during acute ACEi AE attacks (Table 1), a fact that was observed in routinely taken blood samplings from 8 inpatient cases. Two of the patients presented with remarkably high C1-INH activity values, albeit still within the normal range (111 and 122\%; normal range: 70-130\%), whereas the other 6 patients showed C1-INH activity above the upper limit of 130\%. In HAE, a disorder which is also mediated by bradykinin, the role of C1-INH is relatively well known, whereas in the pathomechanism of ACEi AE the function of C1-INH is unclear. In C1-INH-deficient mice, it was shown that inhibition of bradykinin inactivation with captopril enhanced vascular permeability, but mice doubly deficient in both C1-INH and B2R did not demonstrate any increased vascular permeability [24]. Intravenous administration of C1-INH seems to have 
an effect in acute treatment of ACEi AE, but large randomized placebo-controlled studies are not yet available $[25,26]$. C1-INH plays a central role in the regulation of vascular permeability and in the suppression of inflammation [27]. It is a multipotent inhibitor in four physiological systems consisting of serine proteases and their effects: the complement, coagulation, fibrinolytic, and contact activation pathways $[28,29]$. In the case of acute ACEi AE, a feedback loop might explain the increase in C1-INH activity: due to unknown factors, the iatrogenic inhibition of ACE in the degradation of bradykinin becomes clinically relevant, bradykinin levels become high, and edema is mediated. The high bradykinin levels could lead to an increase in C1-INH activity to improve its inhibitory function in bradykinin synthesis. As a trigger factor in the development of ACEi AE, inflammatory reactions have been discussed: strongly increased plasma levels of $\mathrm{C}$-reactive protein were shown in patients presenting to the emergency room with ACEi AE [22]. However, the individual time course of onset has still not yet been clarified. The reason why only a small number of patients with an ACE inhibitor in their regular medication suffer from this side effect is another point that still remains unclear.

Currently, no laboratory value and no validated point-of-care diagnostic test are available to differentiate a bradykinin-mediated from a mast cell-mediated attack [30]. As we observed an interaction of ACE inhibition with C1-INH values in vitro, as well as increased C1-INH activity in patients with ACEi AE during attacks, this marker should be further evaluated.

\section{Statement of Ethics}

The study was approved by the local ethics committee, and all test persons and patients gave written informed consent for their participation as per the Declaration of Helsinki.

\section{Disclosure Statement}

There are no competing interests to declare.

\section{Author Contributions}

M.N.-K., J.H., and J.G. conceived the presented idea. M.N.-K. managed the project until she was on maternity leave, after which J.H. took over to complete the study, analyze the data, and write the manuscript. All authors provided critical feedback and helped shape the analysis and manuscript. G.K. contributed to the interpretation of the results. C.B. recruited the patients for the second study section at the Department of Cardiology, Internal Medicine II, Ulm University Hospital, Ulm, Germany. J.G. and T.K.H. supervised the project.

\section{References}

1 Li EC, Heran BS, Wright JM. Angiotensin converting enzyme (ACE) inhibitors versus angiotensin receptor blockers for primary hypertension. Cochrane Database Syst Rev. 2014 Aug;(8):CD009096.

2 Powers BJ, Coeytaux RR, Dolor RJ, Hasselblad V, Patel UD, Yancy WS Jr, et al. Updated report on comparative effectiveness of ACE inhibitors, ARBs, and direct renin inhibitors for patients with essential hypertension: much more data, little new information. J Gen Intern Med. 2012 Jun;27(6):716-29.

3 Aygören-Pürsün E, Magerl M, Maetzel A, Maurer M. Epidemiology of bradykinin-mediated angioedema: a systematic investigation of epidemiological studies. Orphanet J Rare Dis. 2018 May;13(1):73. 
4 Makani H, Messerli FH, Romero J, Wever-Pinzon O, Korniyenko A, Berrios RS, et al. Meta-analysis of randomized trials of angioedema as an adverse event of renin-angiotensin system inhibitors. Am J Cardiol. 2012 Aug; 110(3):383-91.

5 Brown NJ, Ray WA, Snowden M, Griffin MR. Black Americans have an increased rate of angiotensin converting enzyme inhibitor-associated angioedema. Clin Pharmacol Ther. 1996 Jul;60(1):8-13.

6 Kostis JB, Kim HJ, Rusnak J, Casale T, Kaplan A, Corren J, et al. Incidence and characteristics of angioedema associated with enalapril. Arch Intern Med. 2005 Jul;165(14):1637-42.

7 Brown T, Gonzalez J, Monteleone C. Angiotensin-converting enzyme inhibitor-induced angioedema: A review of the literature. J Clin Hypertens (Greenwich). 2017 Dec;19(12):1377-82.

8 Leeb-Lundberg LM, Marceau F, Müller-Esterl W, Pettibone DJ, Zuraw BL. International Union of Pharmacology. XLV. Classification of the kinin receptor family: from molecular mechanisms to pathophysiological consequences. Pharmacol Rev. 2005 Mar;57(1):27-77.

9 Burch RM, Axelrod J. Dissociation of bradykinin-induced prostaglandin formation from phosphatidylinositol turnover in Swiss 3T3 fibroblasts: evidence for G protein regulation of phospholipase A2. Proc Natl Acad Sci USA. 1987 Sep;84(18):6374-8.

10 Higashida H, Streaty RA, Klee W, Nirenberg M. Bradykinin-activated transmembrane signals are coupled via No or Ni to production of inositol 1,4,5-trisphosphate, a second messenger in NG108-15 neuroblastomaglioma hybrid cells. Proc Natl Acad Sci USA. 1986 Feb;83(4):942-6.

11 Palmer RM, Ferrige AG, Moncada S. Nitric oxide release accounts for the biological activity of endotheliumderived relaxing factor. Nature. 1987 Jun;327(6122):524-6.

12 Bas M, Kojda G, Bier H, Hoffmann TK. [ACE inhibitor-induced angioedema in the head and neck region. A matter of time?]. HNO. 2004 Oct;52(10):886-90. [German]

13 Donaldson VH, Evans RR. A biochemical abnormality in hereditary angioneurotic edema: absence of serum inhibitor of C'1-esterase. Am J Med. 1963 Jul;35:37-44.

14 Maurer M, Magerl M, Ansotegui I, Aygören-Pürsün E, Betschel S, Bork K, et al. The international WAO/EAACI guideline for the management of hereditary angioedema - the 2017 revision and update. Allergy. 2018 Aug; 73(8):1575-96.

15 Bork K. Pasteurized and nanofiltered, plasma-derived C1 esterase inhibitor concentrate for the treatment of hereditary angioedema. Immunotherapy. 2014;6(5):533-51.

16 Björkqvist J, de Maat S, Lewandrowski U, Di Gennaro A, Oschatz C, Schönig K, et al. Defective glycosylation of coagulation factor XII underlies hereditary angioedema type III. J Clin Invest. 2015 Aug;125(8):3132-46.

17 Sinert R, Levy P, Bernstein JA, Body R, Sivilotti ML, Moellman J, et al.; CAMEO Study Group. Randomized Trial of Icatibant for Angiotensin-Converting Enzyme Inhibitor-Induced Upper Airway Angioedema. J Allergy Clin Immunol Pract. 2017 Sep-Oct;5(5):1402-1409.e3.

18 Baş M, Greve J, Stelter K, Havel M, Strassen U, Rotter N, et al. A randomized trial of icatibant in ACE-inhibitorinduced angioedema. N Engl J Med. 2015 Jan;372(5):418-25.

19 Leibfried M, Kovary A. C1 Esterase Inhibitor (Berinert) for ACE Inhibitor-Induced Angioedema: Two Case Reports. J Pharm Pract. 2017 Dec;30(6):668-71.

20 Ostenfeld S, Bygum A, Rasmussen ER. Life-threatening ACE inhibitor-induced angio-oedema successfully treated with icatibant: a bradykinin receptor antagonist. BMJ Case Rep. 2015 Oct;2015:bcr2015212891.

21 Reyher C. Einfluss der ACE-Inhibitoren Quinaprilat und Enalaprilat auf die Funktion neutrophiler Granulozyten und Monozyten [Inaugural-Dissertation]. Giessen: Justus-Liebig-Universität Giessen; 2008.

22 Bas M, Hoffmann TK, Bier H, Kojda G. Increased C-reactive protein in ACE-inhibitor-induced angioedema. Br J Clin Pharmacol. 2005 Feb;59(2):233-8.

23 Bas M, Storck K, Strassen U. Potential Biomarkers for the Diagnosis of Angiotensin-Converting Enzyme Inhibitor-Induced Angioedema. ORL J Otorhinolaryngol Relat Spec. 2017;79(1-2):85-92.

24 Han ED, MacFarlane RC, Mulligan AN, Scafidi J, Davis AE 3rd. Increased vascular permeability in C1 inhibitordeficient mice mediated by the bradykinin type 2 receptor. J Clin Invest. 2002 Apr;109(8):1057-63.

25 Greve J, Bas M, Hoffmann TK, Schuler PJ, Weller P, Kojda G, et al. Effect of C1-esterase-inhibitor in angiotensinconverting enzyme inhibitor-induced angioedema. Laryngoscope. 2015 Jun;125(6):E198-202.

26 Javaud N, Achamlal J, Reuter PG, Lapostolle F, Lekouara A, Youssef M, et al. Angioedema Related to Angiotensin-Converting Enzyme Inhibitors: Attack Severity, Treatment, and Hospital Admission in a Prospective Multicenter Study. Medicine (Baltimore). 2015 Nov; 94(45):e1939.

27 Davis AE 3rd, Mejia P, Lu F. Biological activities of C1 inhibitor. Mol Immunol. 2008 Oct;45(16):4057-63.

28 Davis AE 3rd, Lu F, Mejia P. C1 inhibitor, a multi-functional serine protease inhibitor. Thromb Haemost. 2010 Nov;104(5):886-93.

29 Varga L, Dobó J. C1 inhibitor: quantification and purification. Methods Mol Biol. 2014;1100:189-205.

30 Bernstein JA, Cremonesi P, Hoffmann TK, Hollingsworth J. Angioedema in the emergency department: a practical guide to differential diagnosis and management. Int J Emerg Med. 2017 Dec;10(1):15. 